\title{
Experiences in a Palliative Care Unit for Patients with Dementia
}

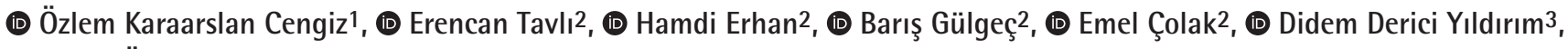 \\ (D) Aynur Özge 4 \\ ${ }^{1}$ Mersin University Faculty of Medicine, Department of Internal Medicine, Clinic of Geriatrics, Mersin, Turkey \\ 2The Dementia-Alzheimer Disabled Care Center, Operated by the Turkish Alzheimer Association's Mersin Branch, Mersin, Turkey \\ 3 Mersin University Faculty of Medicine, Department of Biostatistics and Medical Informatics, Mersin, Turkey \\ ${ }^{4}$ Mersin University Faculty of Medicine, Department of Neurology, Mersin, Turkey
}

\section{Abstract}

Objective: Interest in the concept of palliative care is increasing in patients with advanced dementia; however, the effects of palliative care on the natural course of the disease remain unknown. Therefore, this study aimed to present the 1-year experience of an institutional palliative care unit for patients with dementia.

Materials and Methods: This is a retrospective cross-sectional before-after archive study, which included 35 patients who received palliative care for at least 6 months in the Palliative Care Unit of the Dementia-Alzheimer Disabled Care Center, operated by the Turkish Alzheimer Association's Mersin Branch. Patient data during the palliative care unit admission and the end of 6 months of care were compared.

Results: The mean age of 35 patients ( 14 females and 21 males) was $80.00 \pm 8.47$ years. The average length of stay in the palliative care unit was $10.03 \pm 2.13$ months. Patient weights increased with palliative care $(p<0.001)$. Patients with pain experienced a decrease in their pain levels $(p=0.014)$. Pressure ulcers in $10(28.57 \%)$ patients during admission had improved pressure sore stage and pressure ulcer healing scale ( $p=0.007$ and $p=0.005$, respectively). No new pressure ulcers occurred in any patient. There was a decrease in patients with behavioral symptoms, and no patients developed new behavioral symptoms and/or sleep disorders.

Conclusion: Our results indicate that the quality of life of patients who received multidisciplinary care in an institutional palliative care unit improved.

Keywords: Dementia, palliative care, nutrition, pressure ulcers, pain

\section{Introduction}

One of the most critical health problems in aging societies is dementia, a substantial cause of disability in the elderly. The number of people affected by dementia in the world nearly doubles every twenty years (1-3). Dementia is irreversible and shows a progressive process (4). Regardless of the type of dementia, almost all clinical features are similar in the advanced stage of the disease, and the patient cannot perform even basic daily life activities $(5,6)$. The rate of being placed to care institutions increases parallel with the degree of dependence of the patients $(7,8)$.
Palliative care (PC) is an approach focused on improving the quality of life of patients and their relatives who struggle with progressive and incurable diseases. In palliative care units (PCU), efforts are made to eliminate discomfort symptoms and integrate the psychological and spiritual aspects of care (9). Patients with advanced dementia have many symptoms that cause serious distress for patients and their caregivers. The main symptoms are nutritional problems, weight loss, pain, movement limitations, pressure sores, recurrent infections, sleep problems, and behavioral disorders $(10,11)$.

Most of the PC studies in the world and Turkey have been carried out in general PC centers and often with cancer patients.

Address for Correspondence: Özlem Karaarslan Cengiz, Mersin University Faculty of Medicine, Department of Internal Medicine, Clinic of Geriatrics, Mersin, Turkey

Phone: +90 3242410000 E-mail: ozlemkaraarslancengiz@gmail.com ORCID: orcid.org/0000-0003-0850-1777

Received: 01.09.2021 Accepted: 18.10.2021

Cite this article as: Karaarslan Cengiz Ö, Tavlı E, Erhan H, Gülgeç B, Çolak E, Derici Yıldırım D, Özge A. Experiences in a Palliative Care Unit for Patients with Dementia. Eur J Geriatr Gerontol 2022;4(1):11-17

๑Copyright 2022 by the Academic Geriatrics Society / European Journal of Geriatrics and Gerontology published by Galenos Publishing House. 
However, the PC process in advanced-stage dementia patients is different from the PC process in cancer patients in many aspects. Life expectancy in advanced dementia patients is longer than in terminal stage cancer patients. The rate of functional decline in dementia patients may not always be predictable. Furthermore, cognitive impairments make it more challenging to assess patient symptoms. In patients with advanced dementia, there is even a further increase in the frequency of behavioral and psychological symptoms related to dementia (12-14). Additionally, managing behavioral and psychological symptoms requires a separate perspective and training.

Established within the Dementia-Alzheimer Disabled Care Center of the Mersin Branch of the Turkish Alzheimer's Association, the PCU is the first and only PCU in Turkey that serves only dementia patients. We do not yet have clear information about the direction and extent of the effect of PC on the natural course of the disease in patients with advanced dementia. This study aimed to examine the clinical characteristics of patients followed up in an institutional PCU where all patients are diagnosed with dementia and present the unit's one-year experiences.

\section{Materials and Methods}

A retrospective before-after cross-sectional study was conducted in a single center. Thirty-five dementia patients who stayed for 6 months or longer in the PCU at the DementiaAlzheimer Disabled Care Center of the Turkish Alzheimer Association's Mersin Branch between 21.9.2019 and 21.9.2020 were included. Patients who stayed in the PCU for less than 6 months and who received PC outside of the determined study dates were excluded from the study.

Before starting the research, permission was obtained from the Turkish Alzheimer Association's Mersin Branch DementiaAlzheimer Disabled Care Center, and ethics committee approval was taken from Mersin University Ethics Committee. The guardians of the patients were informed about the research, and their voluntary consent was obtained.

Admission criteria to the PCU have been established by the institution itself: 1- Being constantly in need of invasive or non-invasive mechanical ventilation support, 2- Continuous need for parenteral nutrition/hydration, 3- Being fully bedbound and immobile, and 4- Having moderate or severe pain despite medical treatment. A patient who meets one or more of these criteria can be followed up in this PCU.

Data recorded in the files of the patients were used in our study. Evaluations of the patients during their admission to the PCU were recorded as the "first assessment". After staying in the PCU for at least 6 months, the health records closest to the death date or the date of the completion of the study were accepted as the "last assessment". Patient information was collected with a data collection form prepared by the researchers. Recorded were age, sex, place of stay before the PCU, the duration of stay in the PCU, the disability rate, presence of chronic diseases, drugs used, the reason for leaving the PCU, the Barthel daily living activities index, and the Norton risk assessment scale at the admission to the PCU. In addition, the presence of pressure ulcers, pressure ulcer stage, pressure ulcer scale for healing, oral care, presence of pain, pain severity, analgesic medication use, nutrition, geriatric nutritional risk index (GNRI), height, weight, and neuropsychiatric parameters (communication, behavioral symptoms, sleep) were recorded at the time of admission to the PCU and the closest date to 21.09.2020, the date of stopping data collection.

\section{The disability rate}

The public institution that implements the social security systems that Turkish citizens benefit from is called the Social Insurance Agency. Disability rates were determined by the Social Insurance Agency using the Balthazard Calculation Program (15). The Balthazard Calculation Program is used to calculate the degree of disability of people with more than one disability.

\section{Charlson comorbidity index (CCI)}

The $\mathrm{CCl}$ quantifies comorbidities, thus allowing to assess the impact of comorbidities on prognosis. In this study, the $\mathrm{CCl}$ was calculated to measure the comorbidity burden (16).

\section{Activities of daily living}

The daily living activity levels of the patients were measured with the Barthel activities of daily living index $(17,18)$. The score of this index varies between $0-100$. As the score increases, the degree of dependence of the patient decreases. In this index; 0-20 points are considered fully dependent, 21-61 points severely dependent, 62-90 points moderately dependent, 91-99 points mildly dependent, and 100 points completely independent.

\section{Pressure ulcer}

Norton risk assessment scale was used to determine the risk of pressure ulcers (19). The classification developed by the National Pressure Ulcer Advisory Panel in 2009 was used to determine the stage of the ulcers (20). In patients with more than one pressure ulcer, ulcers with the most advanced stage were recorded. Wound healing was monitored by the pressure ulcer scale for healing (21). The scale considers the area of the wound, the amount of exudate, and the GNRI tissue type. The lowest and highest possible scores are 0 and 17. A high score indicates the severity of the wound. The scale was applied once a week to monitor the evidence of wound healing.

\section{Pain}

Pain intensity was determined using the Pain Assessment in Advanced Dementia Scale, PAINAD $(22,23)$. The patient's breathing pattern, voices produced, facial expression, body 
language, and the need to be calmed are scored on this scale. The patient can get a score between 0 and 10 . Scores between 1-3 are categorized as mild, between 4-6 as moderate, and between $7-10$ as severe.

\section{Nutritional risk assessment}

GNRI is a scale used to determine the risk of malnutritionrelated morbidity and mortality in acute, subacute, and/or long-term follow-up in hospitalized/nursing home patients (24). $\mathrm{GNRI}$ is calculated using the following formula: [1.89 $\mathrm{x}$ albumin $(\mathrm{g} / \mathrm{L})]+[41.7 x$ (weight $(\mathrm{kg}) /$ ideal weight according to Lorent $\left.\left(W_{L 0}\right)\right]\left(W_{L 0}\right.$ : for males: Jeight $(\mathrm{cm})-100-[($ height-150)/4] and for women: height (cm) - 100- [(height-150)/2.5)]. The value calculated according to the GNRI formula is categorized in 4 degrees determining the patient's risk class. $\mathrm{GNRI}<82$ is graded as a major risk, $82 \leq \mathrm{GNRI}<92$ as medium risk, $92 \leq \mathrm{GNRI} \leq 98$ as low risks, and $\mathrm{GNRI}>98$ as no risk.

\section{Oral care}

Oral care was evaluated subjectively by the caring nurses as good, moderate, or bad. If the patient had only bad breath or mild stomatitis (painless erythema), oral hygiene was considered moderate, and if there were more problems, oral hygiene was deemed poor.

\section{Neuropsychiatric parameters}

The communication abilities of the patients were grouped as "verbal communication possible," "speech present but not meaningful-not consistent," "unable to speak but communicating with voices and gestures," and "no communication at all." Agitation, aggression, and apathy were evaluated as behavioral disorders. Parasomnia, insomnia, and hypersomnia were regarded as sleep disorders (25).

\section{Statistics}

Conformity to normal distribution was tested with the Shapiro-Wilk test. Numerical variables meeting the distribution assumption were summarized as mean \pm standard deviation or otherwise as median (minimum-maximum). Categorical variables were summarized in numbers and percentages. The paired samples t-test or Wilcoxon rank-sum test was used in the comparison of two dependent groups according to the distribution assumption. The McNemar test was used to compare dependent variables with two categories. The statistical significance level $p$ was accepted as $<0.05$. All analyzes were made with the Statistica 13.3.1 software (TIBCO Software Inc. CA, USA).

\section{Results}

Forty patients were admitted to the PCU within a year. Five were excluded from the study because they stayed in the PCU for less than 6 months (these patients left the institution due to death). The demographic and clinical characteristics of the 35 patients (aged between 65-95 years) included are shown in Table 1.

Of the 35 patients (31.4\%) who stayed in the PCU for more than 6 months, 11 (31.4\%) left the institution by death. Patients were not transferred home or to another institution. Considering that 40 patients were admitted to the PCU within a year, a total death frequency of 16 patients provided a mortality rate of $40 \%$ (16/40 patients).

At the admission to the PCU, all patients had Bartel daily living activities indexes $<20$ and were wholly dependent. Their mobility physical care indicators at the first and last evaluation are summarized in Table 2, while behavior and sleep disorders and communication levels are summarized in Table 3.

Table 1. Demographic and clinical characteristics of the patients $(n=35)$

\begin{tabular}{|c|c|}
\hline Sex & n (\%) \\
\hline \multirow{2}{*}{$\begin{array}{l}\text { Male } \\
\text { Female }\end{array}$} & $14(40)$ \\
\hline & $21(60)$ \\
\hline Age $^{\#}$ & $80.00 \pm 8.47$ \\
\hline Social security institution disability rate ${ }^{\#}$ & $82.49 \pm 1150$ \\
\hline Place of stay before palliative care unit & n (\%) \\
\hline \multirow{3}{*}{$\begin{array}{l}\text { Home } \\
\text { Another unit of the institution } \\
\text { Hospital }\end{array}$} & $8(22.9)$ \\
\hline & $18(51.4)$ \\
\hline & $9(25.7)$ \\
\hline Charlson comorbidity index ${ }^{*}$ & $2.0(1.0-8.0)$ \\
\hline Comorbid diseases & n (\%) \\
\hline $\begin{array}{l}\text { Dementia } \\
\text { Parkinson's disease } \\
\text { Cerebrovascular accident } \\
\text { Cancer } \\
\text { Type } 2 \text { diabetes } \\
\text { Hypertension } \\
\text { Atherosclerotic heart disease } \\
\text { Heart failure } \\
\text { Chronic obstructive pulmonary disease } \\
\text { Chronic and/or acute renal disease } \\
\text { Thyroid dysfunction }\end{array}$ & $\begin{array}{l}35(100) \\
3(8.6) \\
4(11.4) \\
1(2.8) \\
11(31.4) \\
14(40.0) \\
7(20.0) \\
3(8.6) \\
5(14.3) \\
6(17.1) \\
4(11.4)\end{array}$ \\
\hline Average number of drugs used" & $6.09 \pm 1.884$ \\
\hline Barthel daily living activities index ${ }^{\#}$ & $3.14 \pm 4.382$ \\
\hline Norton pressure scale $\mathrm{e}^{\#}$ & $9.06 \pm 2.209$ \\
\hline Feeding route & n (\%) \\
\hline $\begin{array}{l}\text { Oral + enteral nutrition } \\
\text { Nasogastric feeding tube } \\
\text { Percutaneous endoscopic gastrostomy }\end{array}$ & $\begin{array}{l}4(11.4) \\
1(2.8) \\
30(85.7) \\
\end{array}$ \\
\hline $\begin{array}{l}\text { Mean length of stay in the palliative care unit } \\
\text { (months })^{*}\end{array}$ & $10.03 \pm 2.13$ \\
\hline \multicolumn{2}{|c|}{$\begin{array}{l}\text { "These variables were summarized as mean } \pm \text { standard deviation, }{ }^{*} \text { These variables wer } \\
\text { summarized as median }(25 \mathrm{P}-75 \mathrm{P})\end{array}$} \\
\hline
\end{tabular}




\begin{tabular}{|c|c|c|c|}
\hline Variable & First assessment & Last assessment & $\mathbf{p}$ \\
\hline \multicolumn{4}{|l|}{ Pressure ulcer } \\
\hline $\begin{array}{l}\text { Presence of } \\
\text { pressure ulcer } n \\
(\%)\end{array}$ & $10(28.6)$ & $4(11.4)$ & 0.031 \\
\hline $\begin{array}{l}\text { Pressure ulcer } \\
\text { phase }^{*}\end{array}$ & $3.00(2.00-3.00)$ & $0.00(0.00-1.25)$ & 0.007 \\
\hline $\begin{array}{l}\text { Scale of } \\
\text { improvement* }\end{array}$ & $10.00(7.50-11.50)$ & $0.00(0.00-4.25)$ & 0.005 \\
\hline \multicolumn{4}{|l|}{ Nutrition } \\
\hline Weight\# & $54.93 \pm 11.770$ & $57.39 \pm 10.770$ & $<0.001$ \\
\hline GNRI\# $(n=20)$ & $90.62 \pm 10.997$ & $100.47 \pm 7.169$ & $<0.001$ \\
\hline \multicolumn{4}{|l|}{ Pain } \\
\hline $\begin{array}{l}\text { Patient with pain } \\
\mathrm{n}(\%)\end{array}$ & $19(54.3)$ & $15(42.8)$ & 0.469 \\
\hline Pain scale ${ }^{*}$ & $1.00(0.00-3.00)$ & $0.00(0.00-2.00)$ & 0.014 \\
\hline $\begin{array}{l}\text { Analgesic drug } \\
\text { use } n(\%)\end{array}$ & $4(11.4)$ & $2(5.7)$ & 0.671 \\
\hline \multicolumn{4}{|l|}{ Oral care n (\%) } \\
\hline Good & $18(51.4)$ & $29(82.9)$ & 0.011 \\
\hline Average & 15 (42.9) & $6(17.1)$ & 0.036 \\
\hline Bad & $2(5.7)$ & $0(0.0)$ & 0.475 \\
\hline Total & 35 & 35 & - \\
\hline
\end{tabular}

\section{Discussion}

An average of $20-25 \%$ of patients followed up in PCU have dementia $(26,27)$. However, there is no study evaluating only the PC processes of dementia patients in Turkey. In addition, most of the PCUs in Turkey serve within hospitals, and the hospitalization periods of the patients are much shorter than the PCU within the care centers. In this study, we examined the clinical characteristics of patients followed up in an institutional PCU where all patients were diagnosed with dementia and presented the unit's experience for one year. We concluded that the quality of life increased in patients receiving multidisciplinary care in the institutional PCU.

Verreault et al.'s (28) study in Canada showed that a multidimensional (staff training, pain, oral care, family communication, facilitating nurse) and interdisciplinary intervention program increased end-of-life care and quality of death in the long-term care facility and increased family satisfaction in patients with advanced dementia. The most critical parameters in evaluating institutional care in dementia patients are nutrition, sleep, struggle with behavioral disorders, preservation of patient communication and mobility, prevention of pressure ulcers, pain palliation, follow-up and treatment of chronic diseases, and approach to acute medical problems (29). In this study, evaluations were made on these parameters.

\begin{tabular}{|c|c|c|c|}
\hline Variable & $\begin{array}{l}\text { First } \\
\text { assessment }\end{array}$ & \begin{tabular}{|l} 
Last \\
assessment
\end{tabular} & $\mathbf{p}$ \\
\hline \multicolumn{4}{|l|}{ Behavioral symptom } \\
\hline Agitation & $9(25.7)$ & $7(20.0)$ & 0.777 \\
\hline Aggression & $3(8.6)$ & $1(2.8)$ & 0.595 \\
\hline Apathy & $0(0.0)$ & $0(0.0)$ & - \\
\hline No behavioral disorders & $23(65.7)$ & $27(77.2)$ & 0.423 \\
\hline Total & 35 & 35 & - \\
\hline \multicolumn{4}{|l|}{ Contact } \\
\hline $\begin{array}{l}\text { Unable to communicate } \\
\text { at all }\end{array}$ & $4(11.4)$ & $7(20.0)$ & 0.509 \\
\hline $\begin{array}{l}\text { Communication with voice } \\
\text { and gestures }\end{array}$ & $12(34.3)$ & $15(42.8)$ & 0.627 \\
\hline $\begin{array}{l}\text { Non-meaningful } \\
\text { conversation }\end{array}$ & $7(20.0)$ & $6(17.2)$ & 0.995 \\
\hline $\begin{array}{l}\text { Verbal communication is } \\
\text { established }\end{array}$ & $12(34.3)$ & $7(20.0)$ & 0.282 \\
\hline Total & 35 & 35 & - \\
\hline \multicolumn{4}{|l|}{ Sleeping disorders } \\
\hline Parasomnia & $4(11.5)$ & $4(11.4)$ & 0.717 \\
\hline Insomnia & $2(5.7)$ & $1(2.8)$ & 0.993 \\
\hline Hypersomnia & $1(2.8)$ & $1(2.8)$ & 0.469 \\
\hline No sleep disturbance & $28(80.0)$ & $29(83.0)$ & 0.987 \\
\hline Total & 35 & 35 & - \\
\hline
\end{tabular}

In a study by Koppitz et al. (30), the most common symptoms in the 3-months before death in dementia patients who stayed and died in a nursing home were limitations of movements $(81 \%)$, pain $(71 \%)$, and sleep disturbance $(63 \%)$. As expected, the restriction of movements is higher in PCU. In our study, all patients had movement limitations and were entirely dependent on daily living activities. During the follow-up, only one patient $(1 / 35,2.8 \%)$ slipped from the bed but was not injured.

Patients staying in PCU have a very high risk in terms of pressure ulcers due to movement limitations, applied treatments, and patients' existing chronic diseases. The rate of pressure ulcers in PCU in European and North American Countries is between $58.8 \%$ and $29.9 \%$ (31). The Norton pressure scale enables the evaluation of the risk of developing pressure ulcers in patients admitted to the PCU. It is repeated at regular intervals and in case of changes in the patient's clinical condition. In our study, the Norton pressure scale was 11 in $91.4 \%$ of the patients during admission to the PCU, and these patients were at high risk for pressure ulcer development. During the stay in the PCU, no new pressure ulcers occurred in any patient. Therefore, it was concluded that pressure ulcers can be completely prevented by taking appropriate precautions, even in immobile patients. During admission to the PCU, 10 patients had pressure ulcers. Most of these patients $(7 / 10,70 \%)$ were coming from outside the institution. Pressure ulcer stages and pressure ulcer healing 
scales of the patients were significantly reduced during the follow-up. Nutritional support is also very important in the prevention and treatment of pressure ulcers.

Nutritional problems become inevitable as dementia progresses into the terminal stage. The nutritional status, weight, and swallowing difficulties of the patient should be closely and regularly monitored. It is important for the patient with dementia to have a permanent feeding route at the most appropriate time, without the development of sarcopenia and complications such as aspiration pneumonia due to swallowing difficulty. Although it has not been shown in the literature that percutaneous endoscopic gastrostomy (PEG) tube placement in advanced stage dementia patients improves long-term survival rates, clinical observations suggest that adequate nutrition of patients with swallowing problems and aspiration risk is a comfortable method for the appropriate administration of drugs. For this reason, it has an important place in preventing malnutrition and malnutrition-related morbidity in longterm care institutions (32). In our study, the rate of patients fed through PEG is high. This is because patients who need parenteral nutrition are constantly followed up in the PCU. During admission to the PCU, it was observed that 30 patients were fed via PEG, 4 patients were fed orally, and 1 patient was fed through a nasogastric feeding tube. Since the patients who were fed orally could not meet all their protein and energy needs, these patients were given nutritional supplements with an oral-enteral nutritional product. Two patients who were fed orally over time had a regression in swallowing functions. A PEG tube was placed in one of these patients, and feeding was started through the nasogastric feeding tube in the other. None of the patients had minor or major PEG complications. In a year, only two patients pulled their PEG tubes, which were reinserted. During the follow-ups in the PCU, there was a significant increase in the weight of the patients. GNRI could be calculated in 20 patients whose albumin values were recorded (at admission and follow-up). GNRI values also decreased significantly. Oral health and oral hygiene tend to deteriorate in dementia patients due to various reasons (33). A regular oral care routine is applied in the institution. At the end of a minimum of 6 months of $\mathrm{PC}$, it was observed that oral care was good in $29(82.9 \%)$ of 35 patients and moderate in the remaining $6(17.1 \%)$. There were no patients with bad oral care.

Pain is one of the most important factors affecting the quality of life in PC patients. Its frequency can reach up to $60 \%$ in dementia patients (34). However, patients with advanced dementia rarely express their pain spontaneously. Unexpressed pain may also be reflected in the clinic as depression and agitation. For this reason, it is most appropriate to evaluate pain in patients with advanced-stage dementia using tools such as PAINAD that use parameters such as the patient's voice, breathing style, facial expression, body language, and the need to calm down (22). In our study, according to the evaluation made with the PAINAD scale, 54.3\% of the patients had pain complaints during admission to the PCU and $42.8 \%$ during follow-up. In most of the patients with pain complaints, the pain is mild. Regular physiotherapy exercises under the supervision of a physiotherapist are thought to have a role in the low pain proportions.

With the progression of dementia, an expected course is the decrease or disappearance of verbal communication (35). Not considering patients who could not communicate at the initial evaluation, the level of communication was maintained in about half of the patients during their stay in the PCU. In addition, it was observed that the communication of the two patients progressed from the level of communication with voice and gestures to the level of meaningful speech. The incidence of sleep disturbance has been found to be around $20 \%$. A decrease in patients with behavioral symptoms was found during followup in the PCU. While 12 patients had behavioral symptoms in the first evaluation, 9 had behavioral symptoms in the final assessment. Although the difference was not statistically significant, it was close to the level of significance. Additionally, none of the patients developed new behavioral symptoms during the follow-up, which can be regarded as an indirect indicator that patients receive adequate care (concerning pain, infection, and nutritional management) and feel safe.

In our study, the mortality rate of patients who stayed in the PCU for at least 6 months was 31.4\% (11/35). There was only one patient with chronic shortness of breath and in need of continuous oxygen support.

\section{Study Limitations}

Our study has some limitations. First, our study was conducted in a single center with a small number of patients. Therefore, it does not reflect all dementia patients undergoing PC in Turkey. Second, this is a retrospective study. Family perception could not be evaluated concerning the quality of care. Third, due to the characteristics of the patient group we studied (such as mobilization and communication limitations), patients were evaluated mostly with observational scales. Lastly, some problems frequently encountered in PCU, such as infectious diseases and delirium and factors associated with mortality were not assessed.

\section{Conclusion}

The number of patients with dementia is increasing worldwide and in Turkey. With the increase in the quality of care, the life expectancy of the chronically ill increases too. The importance of PC in patients with advanced dementia is increasingly appreciated. Our study showed that the quality of life increased in patients receiving multidisciplinary care in an institutional 
PCU. Since the natural course of dementia is different from other chronic diseases, it is more appropriate to have a separate PCU for these individuals. For these reasons, there is a need to increase the number of PCUs where dementia patients are cared for. Furthermore, it is necessary to establish PC standards and guidelines for symptom management in individuals with advanced dementia.

\section{Ethics}

Ethics Committee Approval: Ethics committee approval was taken from Mersin University Ethics Committee (no: 431, date: 09/06/2021). The guardians of the patients were informed about the research.

Informed Consent: Informed consent was obtained.

Peer-review: Externally and internally peer-reviewed.

\section{Authorship Contributions}

Surgical and Medical Practices: Ö.K.C., Concept: Ö.K.C., E.T., H.E., B.G., E.Ç., A.Ö., Design: Ö.K.C., E.T., H.E., B.G., E.Ç., A.Ö., Data Collection or Processing: Ö.K.C., E.T., H.E., B.G., E.Ç., Analysis or Interpretation: Ö.K.C., D.D.Y., Literature Search: Ö.K.C., D.D.Y., A.Ö., Writing: Ö.K.C., D.D.Y., A.Ö.

Conflict of Interest: No conflict of interest was declared by the authors.

Financial Disclosure: The authors declared that this study received no financial support.

\section{References}

1. Ferri $C P$, Prince $M$, Brayne $C$, Brodaty $H$, Fratiglioni $L$, Ganguli $M$, Hall $K$, Hasegawa $K$, Hendrie $H$, Huang $Y$, Jorm A, Mathers $C$, Menezes PR, Rimmer E, Scazufca M; Alzheimer's Disease International. Global prevalence of dementia: a Delphi consensus study. Lancet 2005;366:2112-2117.

2. Kua EH, Ho E, Tan HH, Tsoi C, Thng C, Mahendran R. The natural history of dementia. Psychogeriatrics 2014;14:196-201.

3. Tulek Z, Baykal D, Erturk S, Bilgic B, Hanagasi H, Gurvit IH. Caregiver Burden, Quality of Life and Related Factors in Family Caregivers of Dementia Patients in Turkey. Issues Ment Health Nurs 2020;41:741-749.

4. Prince M, Ali GC, Guerchet M, Prina AM, Albanese E, Wu YT. Recent global trends in the prevalence and incidence of dementia, and survival with dementia. Alzheimers Res Ther 2016;8:23.

5. Mitchell SL, Teno JM, Kiely DK, Shaffer ML, Jones RN, Prigerson HG, Volicer L, Givens JL, Hamel MB. The clinical course of advanced dementia. N Engl J Med 2009;361:1529-1538.

6. Erbas Sacar D. Association Between Dementia and Common Geriatric Syndromes. Eur J Geriatr Gerontol 2020;2:71-76.

7. Karadakovan A. Care of the Demensive Elderly. Turkiye Klinikleri J GeriatrSpecial Topics 2015;1:67-71.

8. Sampson EL, Candy B, Davis S, Gola AB, Harrington J, King M, Kupeli N, Leavey G, Moore K, Nazareth I, Omar RZ, Vickerstaff V, Jones L. Living and dying with advanced dementia: A prospective cohort study of symptoms, service use and care at the end of life. Palliat Med 2018;32:668-681.

9. Stewart JT, Schultz SK. Palliative Care for Dementia. Psychiatr Clin North Am 2018;41:141-151.
10. Hanson E, Hellström A, Sandvide $\AA$, Jackson GA, MacRae R, Waugh A, Abreu W, Tolson D. The extended palliative phase of dementia - An integrative literature review. Dementia (London) 2019;18:108-134.

11. Ellis-Smith $C$, Evans $C J$, Bone $A E$, Henson LA, Dzingina M, Kane PM, Higginson IJ, Daveson BA; BuildCARE. Measures to assess commonly experienced symptoms for people with dementia in long-term care settings: a systematic review. BMC Med 2016;14:38.

12. van der Steen JT. Dying with dementia: what we know after more than a decade of research. J Alzheimers Dis 2010;22:37-55.

13. Hessler JB, Schäufele $M$, Hendlmeier I, Junge $M N$, Leonhardt $S$, Weber J, Bickel H. Behavioural and psychological symptoms in general hospital patients with dementia, distress for nursing staff and complications in care: results of the General Hospital Study. Epidemiol Psychiatr Sci 2018;27:278287.

14. Erel M, Marcus EL, Dekeyser-Ganz F. Barriers to palliative care for advanced dementia: a scoping review. Ann Palliat Med 2017;6:365-379.

15. Calculation of disability in case of more than one disability. Regulation on Health Board Reports to be Given to Disabled Persons. Official Gazette dated 06.02.1998 and numbered 10746. http://www.hukuki.net/law/9810746.35. text.asp.

16. Charlson ME, Pompei P, Ales KL, MacKenzie CR. A new method of classifying prognostic comorbidity in longitudinal studies: development and validation. J Chronic Dis 1987;40:373-383.

17. Mahoney Fl, Barthel DW. Functional Evaluation: The Barthel Index. Md State Med J 1965;14:61-65.

18. Küçükdeveci AA, Yavuzer $G$, Tennant $A$, Süldür $N$, Sonel $B$, Arasil T. Adaptation of the modified Barthel Index for use in physical medicine and rehabilitation in Turkey. Scand J Rehabil Med 2000;32:87-92.

19. Norton $D$, McLaren R, Exton-Smith AN. An investigation of geriatric nursing problems in hospitals. London 7 National Corporation for the Care of Old People; 1975.

20. Stausberg J, Kiefer E. Classification of pressure ulcers: a systematic literature review. Stud Health Technol Inform 2009;146:511-515.

21. Thomas DR, Rodeheaver GT, Bartolucci AA, Franz RA, Sussman C, Ferrell BA, Cuddigan J, Stotts NA, Maklebust J. Pressure ulcer scale for healing: derivation and validation of the PUSH tool. The PUSH Task Force. Adv Wound Care 1997;10:96-101.

22. Warden V, Hurley AC, Volicer L. Development and psychometric evaluation of the Pain Assessment in Advanced Dementia (PAINAD) scale. J Am Med Dir Assoc 2003;4:9-15.

23. Büyükturan Ö, Naharci Mi, Büyükturan B, Kirdi N, Yetiş A. The Turkish Version of Pain Assessment in Advanced Dementia (PAINAD) Scale. Noro Psikiyatr Ars 2018;55:271-275.

24. Bouillanne O, Morineau G, Dupont C, Coulombel I, Vincent JP, Nicolis I, Benazeth S, Cynober L, Aussel C. Geriatric Nutritional Risk Index: a new index for evaluating at-risk elderly medical patients. Am J Clin Nutr 2005:82:777-783.

25. McCleery J, Sharpley AL. Pharmacotherapies for sleep disturbances in dementia. Cochrane Database Syst Rev 2020;11:CD009178.

26. Harrison KL, Bull JH, Garrett SB, Bonsignore L, Bice T, Hanson LC, Ritchie CS. Community-Based Palliative Care Consultations: Comparing Dementia to Nondementia Serious IIInesses. J Palliat Med 2020;23:1021-1029.

27. Göksel F, Şenel G, Oğuz G, Özdemir T, Aksakal H, Türkkanı MH, Küçük A, Eğin ME, Gultekin M, Silbermann M. Development of palliative care services in Turkey. Eur J Cancer Care (Engl) 2020;29:e13285.

28. Verreault $R$, Arcand M, Misson L, Durand PJ, Kroger E, Aubin M, Savoie M, Hadjistavropoulos T, Kaasalainen S, Bédard A, Grégoire A, Carmichael PH. Quasi-experimental evaluation of a multifaceted intervention to improve quality of end-of-life care and quality of dying for patients with advanced dementia in long-term care institutions. Palliat Med 2018;32:613-621. 
29. Heffels JCF, Everink IHJ, Oosterloo M, Roos RAC, Schols JMGA. Measuring the quality of care in nursing home residents with early-onset neurodegenerative diseases: a scoping review. BMC Palliat Care 2020;19:25.

30. Koppitz A, Bosshard G, Schuster DH, Hediger H, Imhof L. Type and course of symptoms demonstrated in the terminal and dying phases by people with dementia in nursing homes. Z Gerontol Geriatr 2015;48:176-183.

31. Demarré L, Van Lancker $A$, Van Hecke A, Verhaeghe S, Grypdonck M, Lemey J, Annemans L, Beeckman D. The cost of prevention and treatment of pressure ulcers: A systematic review. Int J Nurs Stud 2015;52:1754-1774.

32. Kurien M, Williams J, Sanders DS. Malnutrition in healthcare settings and the role of gastrostomy feeding. Proc Nutr Soc 2017;76:352-360.
33. Delwel S, Binnekade $\Pi$, Perez RSGM, Hertogh CMPM, Scherder EJA, Lobbezoo F. Oral hygiene and oral health in older people with dementia: a comprehensive review with focus on oral soft tissues. Clin Oral Investig 2018;22:93-108.

34. Moens K, Higginson IJ, Harding R; EURO IMPACT. Are there differences in the prevalence of palliative care-related problems in people living with advanced cancer and eight non-cancer conditions? A systematic review. J Pain Symptom Manage 2014;48:660-677.

35. Eisenmann $Y$, Golla $H$, Schmidt $H$, Voltz $R$, Perrar KM. Palliative Care in Advanced Dementia. Front Psychiatry 2020;11:699. 